\title{
Peritonite pós-cobertura em cadela Boxer apresentando síndrome de ovário remanescente (SOR)
}

\author{
Post breeding peritonitis in a Boxer bitch with ovarian remnant syndrome (ORS) \\ Carmo Emanuel Almeida Biscarde', Rosiára Rosária Dias Maziero', Nereu Carlos Prestes', \\ Maria Clara Costa Mattos', Gabriel Augusto Monteiro', Ulisses Jorge Pereira Stelmann², \\ Gustavo Henrique Marques Araújo' \& Sony Dimas Bicudo'
}

\begin{abstract}
RESUMO
A síndrome do ovário remanescente (SOR) é definida como a persistência da atividade ovariana em fêmeas castradas cirurgicamente (OSH), nas quais permanece parte do ovário ou todo ele se vasculariza, tornando-se funcional, podendo ocorrer em gatas e cadelas. Esta condição proporciona a continuação de sinais indesejáveis ligados ao estro, como atração de machos, secreção sanguinolenta, inquietação, pseudociese, dentre outros. O tratamento definitivo desta síndrome é a remoção cirúrgica do tecido ovariano presente. Este procedimento deve ser realizado na fase estrogênica do ciclo estral, com a finalidade de facilitar a localização do tecido ovariano com os folículos presentes. Não há referências na literatura sobre as consequências de uma possível cobertura, portanto descreve-se este caso com o objetivo relatar uma peritonite desencadeada após monta natural em cadela portadora de SOR, atendida no Hospital Veterinário da Faculdade de Medicina Veterinária e Zootecnia da UNESP, campus Botucatu, São Paulo, Brasil.
\end{abstract}

Descritores: síndrome do ovário remanescente (SOR), peritonite, cadela.

\begin{abstract}
The ovarian remnant syndrome (ORS) is defined as the persistence of ovarian activity in surgically spayed females, in which part or the entire ovary remains after the surgical procedure. ORS is characterized as a neo-vascular formation that promotes the organ's functions again, and may occur in cats and dogs. This condition causes the return of all undesirable signs of estrus, like male attraction, vaginal secretion (proestral bleeding), anxiety, pseudocyesis, among other symptoms. The recommended treatment is the surgical removal of the remaining ovary tissue. However, this procedure should be performed at the estrogenic stage of the cycle, when the remaining ovary tissue is enlarged due to the presence of follicles, which facilitates its location. Apparently there are no papers on the consequences of an undesirable breeding. Thus, the objective of this article was to report a case of peritonitis in a bitch with ORS after natural breeding, referred to the Hospital Veterinário da Faculdade de Medicina Veterinária e Zootecnia da UNESP, campus Botucatu, São Paulo, Brazil.
\end{abstract}

Keywords: ovarian remnant syndrome (ORS), peritonitis, bitch. 000 Botucatu, SP, Brasil. CORRESPONDÊNCIA: C.E.A. Biscarde [ceabiscarde@yahoo.com.br - Fax: +55 (14) 38116249 ]. 


\section{INTRODUÇÃO}

A síndrome do ovário remanescente (SOR) é uma condição iatrogênica observada após ovariosalpingohisterectomia (OSH) com manifestações de estro [14]. Esta síndrome foi descrita em gatas [3], cadelas [8] e mulheres [11]. Em humanos, esta patologia é mais comumente descrita, uma vez que as pacientes submetidas a este tipo de cirurgia apresentam elevado grau de inflamação, consequentemente, uma maior vascularização na região pélvica, seja por endometriose ou doença inflamatória pélvica (PID) [5], sendo mais difícil a retirada desse tecido. A sintomatologia principal desta síndrome em mulheres é dor abdominal crônica [16].

A SOR ocorre devido à revascularização do tecido ovariano [13]. Assim, esmagamentos ovarianos durante a OSH podem causá-la, da mesma forma quando há presença de tecido ovariano acessório localizado no ligamento largo $[1,4]$. O procedimento cirúrgico é mais difícil em fêmeas obesas e animais que apresentam pedículo ovariano de difícil acesso, porém não há correlação positiva entre estas características e a ocorrência da SOR [15]. Em estudo com 46 casos de SOR, observou-se que os tecidos remanescentes possuíam igual prevalência em ambos ovários, da mesma forma, não houve correlação da sua ocorrência com a experiência dos cirurgiões, em que menos da metade dos casos foram realizados por veterinários graduados há menos de 5 anos [6]. Neste levantamento, o autor observou um maior número de gatas com a síndrome do que cadelas, nos quais, em 31 dos casos, os ovários apresentavam folículos, facilitando, portanto, a excisão do tecido. Este relato de caso descreve peritonite após cobertura em cadela Boxer com SOR.

\section{RELATO DO CASO}

Uma cadela Boxer branca com 3 anos de idade, $30,5 \mathrm{~kg}$, proveniente da cidade de Conchas, SP, foi atendida no ambulatório de pequenos animais da área de Reprodução Animal da Faculdade de Medicina Veterinária e Zootecnia (FMVZ) - UNESP -, Botucatu, SP, com histórico de ter sido castrada há um ano, em virtude de uma piometra. $\mathrm{O}$ animal, até então, nunca havia entrado em cio, devido ao uso de anticoncepcional a base de acetato de melegenstrol. Na primeira consulta, a queixa principal foi a presença de corrimento vaginal marrom e atração de machos sem permitir a cobertura, sem qualquer alteração clínica.
A suspeita de SOR foi reforçada após a realização da citologia vaginal, encontrando-se mais de $80 \%$ de células epiteliais superficiais e ao exame ultrassonográfico, em que se observou área hipoecóica próxima à base do rim direito. Havia áreas hiperecóicas próximo ao polo caudal do rim esquerdo. Ao executar a avaliação ultrassonográfica da cavidade abdominal, descartou-se piometra de coto uterino relatada como uma das complicações da SOR [9], optando-se por recomendações de ordem conservativas.

Houve retorno do animal 16 dias após a primeira consulta, com histórico de ter sido coberta há 6 dias, apresentando apatia, hipodipsia, anorexia, FC: 124bpm, FR: $40 \mathrm{mpm}$, temperatura de $39.5^{\circ} \mathrm{C}$, mucosas congestas, descarga vulvar de característica purulenta. Ao exame ultrassonográfico, foi observada elevada ecogenicidade da região caudal do abdômen. O hemograma e o bioquímico sérico para ureia e creatinina foram realizados, apresentando leucocitose com 15.000 leucócitos por $\mu \mathrm{L}$, destes 12.380 eram segmentados. A laparotomia observou-se áreas de intensa hiperemia por toda a cavidade e líquido serossanguinolento acumulado (Figura 1), encontrando o coto uterino rompido (Figura 2) e aderido a bexiga. Ao examinar o polo caudal do rim esquerdo, com áreas de aderências, não foi localizado tecido ovariano. Já no polo caudal do rim direito, havia tecido ovariano com presença de folículos (Figura 3), procedendo-se a retirada do mesmo para resolução da SOR. Para tratamento da peritonite, a cavidade abdominal foi lavada com $1 \mathrm{~L}$ de solução fisiológica a $0,9 \%$ e administrou-se via intravenosa metronidazol $(10 \mathrm{mg} / \mathrm{kg})$ durante o procedimento cirúrgico. Ao final do procedimento, a síntese da cavidade foi realizada com pontos em "x" tipo Sultan, reaproximação e redução de espaço morto do subcutâneo e sutura da pele com pontos simples separados.

No pós-operatório, foi receitado enrofloxacina ${ }^{1}$ $(10 \mathrm{mg} / \mathrm{kg})$, durante 10 dias, e uso de meloxicam ${ }^{2}$ $(0,1 \mathrm{mg} / \mathrm{kg})$ durante 3 dias. O retorno foi marcado para retirada dos pontos cirúrgicos da pele, nesta ocasião, o animal apresentou parâmetros clínicos e hemograma dentro da normalidade com 4.200 leucócitos por $\mu \mathrm{L}$ destes 3.150 eram segmentados.

\section{DISCUSSÃO}

O diagnóstico da SOR está relacionado aos sinais de estro aliado com referência de OSH prévia. Além disso, observa-se crescimento da glândula mamária e 


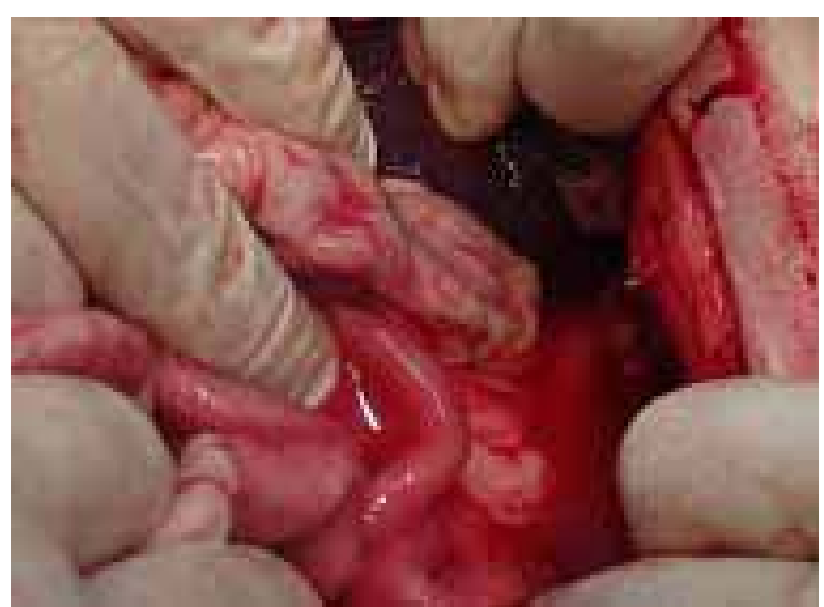

Figura 1. Cavidade abdominal com grande quantidade de líquido serossanguinolento.

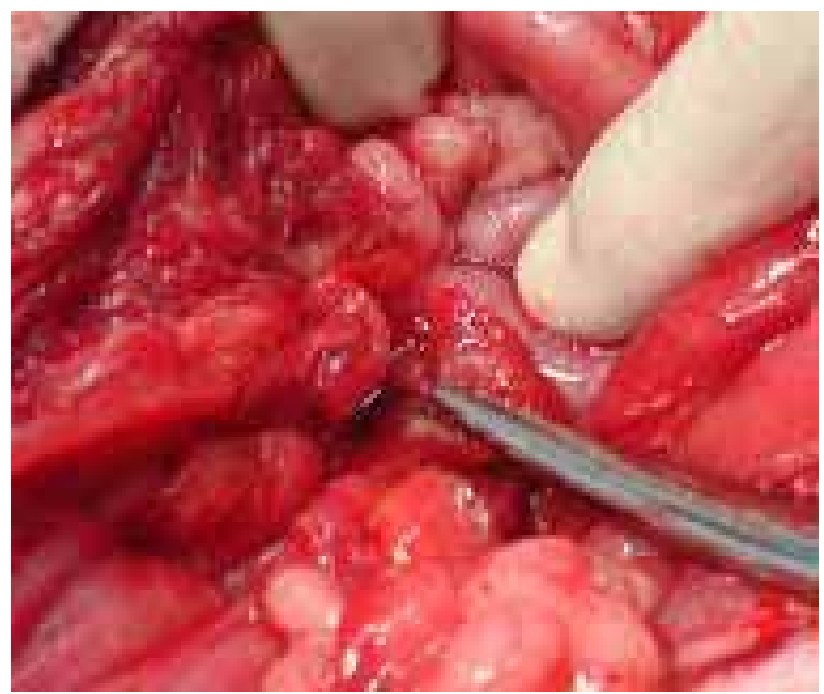

Figura 2. Coto uterino rompido devido à monta e aderido a bexiga.

pseudociese recorrente. Células epiteliais superficiais cornificadas são observadas na citologia vaginal. A administração de GnRH ou HCG estimulando a resposta de um possível tecido ovariano [2], além da ultrassonografia para localização do órgão são métodos auxiliares no diagnóstico [14], porém o último se restringe a animais em estro ou diestro, pois nessas fases a presença de folículos ou corpos lúteos apresentando tamanho considerável facilita a sua visualização. Caso o animal não se encontre nessas fases do ciclo estral, o exame ultrassonográfico será de pouca valia, logo o método para definir o diagnóstico e tratamento da SOR deverá ser a laparotomia exploratória [7].

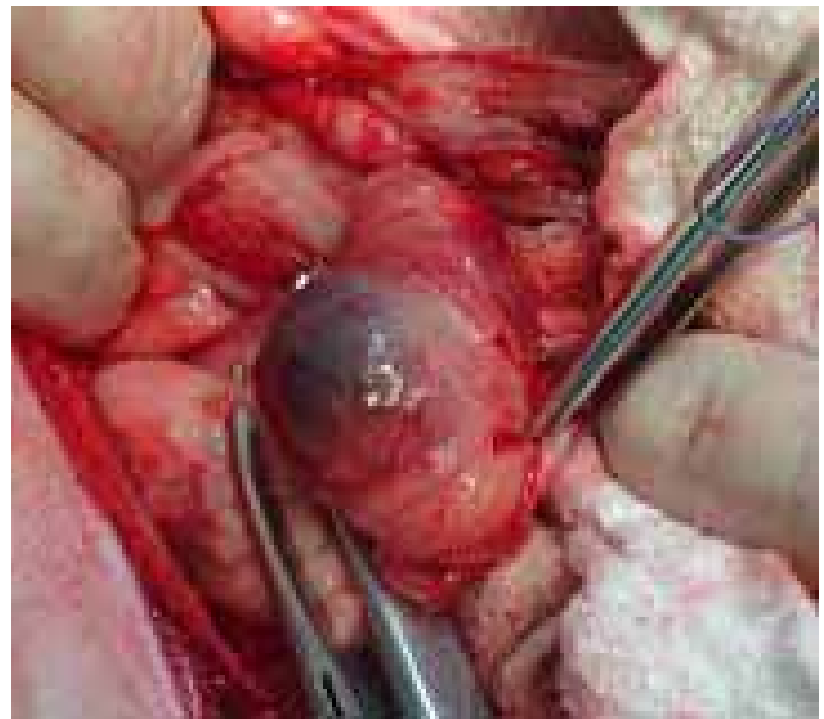

Figura 3. Localização do tecido ovariano remanescente.

Não são raros os casos de animais acometidos pela SOR, exibirem sinais de pseudociese após o estro [15]. A permanência de tecido ovariano pode possibilitar a ocorrência de tumor de células da granulosa [10], além de proporcionar um maior risco de desenvolvimento de neoplasias mamárias [12].

O diagnóstico diferencial está associado a condições que causam descarga vulvar como: neoplasias vaginais, vaginite, embora tenha relato de ocorrência da SOR associada a uma vaginite crônica em uma cadela poodle toy [9], além de piometra de coto uterino, traumas diversos, tratamentos com estrógeno exógeno e coagulopatias [4].

A laparotomia exploratória para uma possível visibilização do tecido ovariano, procedendo a sua retirada, é a terapia preconizada, realizada preferencialmente no proestro ou diestro [4].

A presença de corrimento vaginal e atração de machos sugeriu um caso de SOR, fato confirmado após o exame ultrassonográfico e laparotomia exploratória [14]. A cadela que apresenta SOR não deve ser coberta, sendo necessária laparotomia exploratória no estro ou diestro para localização e retirada do tecido ovariano remanescente.

\section{NOTAS INFORMATIVAS}

${ }^{1}$ Baytril ${ }^{\circledR}$, Bayer S.A., São Paulo, SP, Brasil

${ }^{2}$ Maxicam 0,5 mg ${ }^{\circledR}$, Ouro Fino Pet S.A., Cravinhos, SP, Brasil.

\section{REFERÊNCIAS}

1 Alpem H. 1990. Supernumerary ovary: A case report. Journal of Reproduction Medicine. 35 (3): 283-285.

2 England G.C.W. 1997. Confirmation on ovarian remnant syndrome in the queen using hCG administration. Veterinary Record. 141 (12): 309-310. 
Biscarde C.E.A., Maziero R.R.D., Prestes N.C., Mattos M.C.C., Monteiro G.A., Stelmann U.J.P., Araújo G.H.M. \& Bicudo S.D. 2009. Peritonite pós-cobertura em cadela Boxer apresentando síndrome de ovário... Acta Scientiae Veterinariae. 37(4):375-378.

3 Heffelfinger D.J. 2006. Ovarian Remnant in a 2-years-old Queen. Canadian Veterinary Journal. 47 (2): $167-167$.

4 Lopes M.D. \& Macedo L.P. 2004. Síndrome del ovario remanente en perras y gatas. In: Gobello C. (Ed). Temas de reproducción de caninos y felinos por autores latinoamericanos. Buenos Aires: Gráfica Latina, pp.61-64.

5 Nezhat C., Kearney S., Malik S. \& Nezhat F. 2005. Laparoscopic management of ovarian remnant. Fertility and Sterility. 83 (4): 973-978.

6 Miller D.M. 1995. Ovarian remnant syndrome in dogs and cats: 46 cases (1988-1992). Journal of Veterinary Diagnostic Investigation. 7 (4): 572-574.

7 Oliveira K.S. 2007. Síndrome do resto ovárico. Acta Scientiae Veterinariae. 35 (Supl 2): s273-s274.

8 Pearson H. 1973. The complications of ovariohisterectomy in the bitch. Journal of Small Animal Practice. 14 (5): $257-266$.

9 Perkins N.R. \& Frazer G.S. 1995. Ovarian remnant syndrome in toy poodle a case report. Theriogenology. 44 (3): $307-312$.

10 Pluhar G.E., Memon M.A. \& Wheaton L.G. 1995. Granulosa cell tumor in an ovariohysterectomized dog. Journal of American Veterinary Medical Association. 207 (8): 1063-1065.

11 Price F., Edwards R. \& Buchsbaum H. 1990. Ovarian remnant syndrome: difficulties in diagnosis and management. Obstetrical \& Gynecological Survey. 45 (3): 151-156.

12 Sangster C. 2005. Ovarian remnant syndrome in a 4-year-old bitch. Canadian Veterinarian Journal. 46 (1): $62-64$.

13 Shemwell R.E. \& Weed J.C. 1970. Ovarian remnant syndrome. Obstetrics and Gynecology. 39 (2): $299-303$.

14 Sontas B.H., Guburlak K. \& Ekici H. 2007. Ovarian remnant syndrome in the bitch: a literature review. Archivos de Medicina Veterinaria. 39 (2): 99-104.

15 Wallace M.S. 1991. The ovarian remnant syndrome in the bitch and queen. Veterinary Clinics of North America: Small Animal Practice. 21(3): 501-507.

16 Webb M. 1989. Ovarian remnant syndrome. The Australian and New Zealand Journal of Obstetrics and Gynecology. 29 (4): 433-435. 